\title{
Examining Characteristics of Resilience among University Students: An International Study
}

\author{
Aileen M. Pidgeon1, Natasha F. Rowe1, Peta Stapleton1, Heidi B. Magyar², Barbara C. Y. Lo³ \\ ${ }^{1}$ GradDipPsychSc, Bond University, Gold Coast, Australia \\ ${ }^{2}$ University of Florida, Gainesville, USA \\ ${ }^{3}$ The University of Hong Kong, Hong Kong School of Psychology, Bond University, Gold Coast, Australia \\ Email: apidgeon@bond.edu.au
}

Received August 2014

\section{Abstract}

Attending university is a particularly stressful time due to unique emergent stressors such as changes in environment, loss or diminishment of social support networks, academic pressures, developing peer relationships, and financial management. There is growing recognition that these common stressors may have deleterious effects on the mental health of students. Resilience, a personality characteristic that moderates the negative effects of stress and promotes adaptation, has been associated with increased psychological well-being. Despite a growing body of research on resilience and its clinical significance in preventing mental health problems, relatively little is known about contributing factors for resilience in well-adjusted university students. This current study examined the characteristics of university students reporting high and low resilience for elucidating its clinical implications in preventing mental health problem, primarily focusing on potentially modifiable psychosocial variables. An international sample of 214 university students recruited from Australia, the United States of America, and Hong Kong universities completed measures of resilience, perceived social support, campus connectedness, and psychological distress. Results of a one-way between groups multivariate analysis of variance revealed that perceived social support, campus connectedness, and psychological distress accounted for a significant proportion (36\%) of the variance between the high and low resilience groups of university students. University students with low levels of resilience reported significantly lower levels of perceived social support, campus connectedness, and higher levels of psychological distress, in comparison to university students with high levels of resilience. Findings offer important implications for the development of resilience-based interventions among university students.

\section{Keywords}

Resilience, Psychological Distress, Perceived Social Support, Campus Connectedness, University Students 


\section{Introduction}

Extensive research with university students indicates that psychological distress is a major concern during the transition to university due to the multiple changes students face across personal, social, and emotional facets of their lives [1]-[3]. In addition to academic demands, university students experience novel stressors and challenges such as, financial and living arrangements, the formation of new social networks, and adapting to new familial and societal roles [4].

With growing research on the mental health of university students, empirical work on resilience has gained recognition as a framework for examining why some students are successful in adapting to university, while others face greater challenges [5]. Previous research indicates that a successful adjustment to university is not only related to resilience, but is also the result of modifiable psychosocial factors including peer connectedness, feelings of belonging to the university, perceived social support, and psychological wellbeing [6]. Due to the increasing pressures placed on university students, mental health issues among this population are a growing concern, with global research indicating an increase in depression, anxiety, and stress [7]-[9]. For example, research indicates that Australian university students' report higher levels of stress, depression, and anxiety, than the general population [5] [16] [17] and American university students report high levels of depression, generalised anxiety disorder, panic disorders, and suicidal ideation. Furthermore, university students in Hong Kong report high prevalence rates of anxiety, depression, and stress [43]. Therefore, gaining an understanding of the key modifiable psychosocial factors associated with higher levels of resilience which promotes positive adjustment among the university population is warranted.

\subsection{Resilience}

Resilience is a key variable associated with the adaptation to the university environment [10]. Research shows resilience reduces the risk of psychological distress, assists with the management of academic demands, enhances academic outcomes, while also facilitating effective coping strategies when faced with academic pressures [11] [12]. In the absence of resilience, the stressors university students face have the potential to negatively affect their mental health, increase psychological distress, and result in greater adjustment problems [13] [14].

Previous research on resilience has primarily focused on individuals affected by short and long-term adversities [15]. University students are exposed to long-term adversities, such as academic stressors and environmental pressures [1]. Although a universal definition of resilience does not exist, resilience is widely considered as an individual's capacity to overcome adversities and successfully adapt to their environment [16].

Definitions of resilience range from a set of traits, an outcome, or a dynamic process that involves the exposure to stress or adversity, followed by successful adaptation [17] [18]. Connor and Davidson [19] define resilience as personal qualities that enable individuals to thrive when faced with adversity. While Gilligan [20], defines resilience as the ability to respond adequately and perform successfully in the face of adversity, or to exceed expectations during hardships. Additionally, researchers have viewed resilience as a protective buffer that protects individuals against adversity [21]. Overall, global findings suggest that resilience in the university environment is positively associated with greater mental health, as well as successful transition and adjustment to university life [10] [22] [23].

\subsection{Perceived Social Support}

Research shows a strong link between resilience and perceived social support, as perceived social support also contributes to one's ability to deal with adversities [12] [24]-[27]. Perceived social support has been identified as a popular construct within the field of educational psychology, as it reflects an interaction between students and their environment. This interaction is shown by perceived social support's buffering effects on the relationship between, psychological distress and resilience among university students [26].

Perceived social support is defined as an individual's perception of physical and emotional care received from family, friends, and significant others [28]. Perceived social support is strongly associated with increased psychological wellbeing compared to enacted social support. Enacted social support is defined as the qualitative nature of relationships with others involving interpersonal transactions of resources of support, which has been associated with negative psychological outcomes and decreased wellbeing [29]. Assessing an individual's perception about themselves and their environment is an important indicator of mental health status, with greater mental health outcomes associated with positive perception of one's self and environment [30]. Therefore, ex- 
amining an individual's perceived level of social support, rather than enacted social support, provides a greater insight into an individual's thoughts, perceptions, and beliefs, which in turn are associated with resilience [31].

Global findings suggest that perceived social support acts as a buffer by moderating the negative effect of stress [32]. When applied to the university context, global findings reveal that perceived social support increases internal resources of coping which in turn reduced the impact of stressors [12].

\subsection{Campus Connectedness}

In addition to the well-established constructs of resilience and perceived social support, a novel construct examined in the university context is campus connectedness. Although appearing similar to perceived social support, campus connectedness measures beyond this dimension by examining an individual's perception of fitting in and belonging with others within the university environment [33]. In accordance with the Campus Connectedness Scale [33], campus connectedness is operationally defined as the ability to develop quality relationships with peers, fitting in, belonging, and feeling connected to campus life. Fitting in and having a sense of belonging is important during the transition period into university, as social connectedness facilitates greater levels of resilience [34].

Theories surrounding university attrition have placed great emphasis on the importance of both social and academic integrations of students into the university context [35] [36]. Literature exploring attrition in university students suggests that a students' sense of connectedness, particularly in their transition to university, is significantly important in fostering increased academic motivation and higher levels of success [1]. Although connectedness is often considered a positive characteristic that facilitates resilience, there is limited research on connectedness and its association with resilience and mental health outcomes, within the university context. However, a series of studies assessing connectedness and resilience within the school environment have revealed that connectedness significantly influences academic and psychological outcomes for students [37] [38].

\subsection{Psychological Distress}

In comparison to the limited literature between resilience and campus connectedness, the link between resilience and psychological distress is well established [22] [37]. Psychological distress in university students is operationalised by three distinct negative emotional states including: depression, anxiety, and stress. For the purpose of the present study, depression is operationalised as prolonged feelings of despondency through assessment of dysphoria, hopelessness, self-deprecation, devaluations of life, lack of interest, anhedonia, and inertia. Anxiety is defined as increased worry, apprehension or fear, and operationalised through measurement of autonomic arousal, situational anxiety, skeletal muscle effect, and subjective experience of anxious effect [38]. Finally, the present study operationalises stress as a state of mental and emotional tension resulting from demanding or adverse circumstances. The assessment of stress includes the investigation of the following emotional states: being easily agitated, nervous arousal, difficulty relaxing, irritability, and impatience [38]. Due to the interrelationship of these variables within the university context, the present study examined psychological distress, which has often been regarded as a comprehensive term utilised within the literature when referring to depression, anxiety, and stress, when these factors are not of interest in isolation [39].

Research suggests that rates of psychological distress are increasing within university populations, with many studies showing the negative effects of such distress on student's experiences at university [40]. According to a nationwide survey conducted by the American College Health Association (2012), approximately 30\% of college students indicated experiencing depression, with an additional 50\% reporting experiencing overwhelming anxiety. Findings also revealed that due to these stressors, seven per cent of American college students had considered suicide [41].

Research investigating the mental health status of university students in China claims suicide is one of the highest causes of death in people aged 15 to 34 years, accounting for $19 \%$ of recorded deaths in this age group [42]. Due to the alarming rates of suicide in this population, Wong, Cheung, Chan, Ma, and Tang [43] investigated the prevalence of depression, anxiety, and stress in a sample of 7915 university students in Hong Kong. Results found that $21 \%$ of university students reported moderate to severe levels of depression, $41 \%$ reported moderate to severe anxiety, and $27 \%$ reported moderate to severe levels of stress. In support of these statistics, a study conducted by Chen et al. [44] investigated the prevalence of depression in a sample of 5245 Chinese university students. Results revealed $40.1 \%$ of university students met the classification for borderline clinical de- 
pression.

With statistics indicating such high prevalence of psychological distress in university populations, and subsequently high rates of suicide in this age group, adequate support services are needed [45]. Several studies have demonstrated that university students with higher levels of psychological distress report lower levels of resilience, poorer relationships with peers, greater adjustment problems, and higher attrition rates [22] [40] [45].

The research linking lower levels of psychological distress with higher levels of resilience, suggests that resilience is a key factor in the university environment and provides an important framework for determining why some students experience low levels of psychological distress, and why other university students experience high levels of distress during their experience at university [16]. Despite many studies suggesting resilience is a key factor in reducing psychological distress, few studies have explored the characteristics of resilient university students. In addition, no studies to date have examined the relationship between campus connectedness, perceived social support, and psychological distress within the university context. Furthermore, even less is known as to how, campus connectedness and resilience relate to one another in the university context. To the author's knowledge, no studies to date have examined this association.

\subsection{The Current Study}

The present study aimed to increase our understanding of the characteristics of resilience among university students by examining high vs low levels of resilience in relation to perceived social support, campus connectedness, and psychological distress.

H1. It is predicted that significant positive correlations will exist between resilience, perceived social support, and campus connectedness, while a significant negative correlation will exist between resilience and psychological distress.

H2. It is predicted that in comparison to university students with high levels of resilience, university students with low levels of resilience would report significantly:

1. Higher levels of psychological distress.

2. Lower levels of perceived social support.

3. Lower levels of campus connectedness.

\section{Method}

\subsection{Participants}

Participants comprised of 214 university students aged 18 to 59 years $(M=22.03, S D=5.48)$ recruited from Bond University (Australia), the University of Florida (USA), and the University of Hong Kong (Hong Kong). Of this sample, 166 (77.6\%) participants were female and 48 (22.4\%) participants were male. Inclusion criteria required participants to be over 18 years of age.

\subsection{Measures}

The Resilience Scale (RS). The RS is a 25-item self-report scale, developed by Wagnild and Young [16], designed to measure an individual's resilience level. The RS uses a 7-point Likert Scale and provides a total score of resilience, ranging from 25 to 175, with higher scores indicative of higher levels of resilience.

The Multidimensional Scale of Perceived Social Support (MSPSS). The MSPSS is a 12-item self-report scale that measures an individual's subjective levels of perceived social support [49]. Items on the MSPSS are scored using a 7-point Likert Scale. The scores for the MSPSS range from 12 to 84 . A total score of perceived social support is calculated through summation of the 12 items, with higher scores indicative of higher perceived social support [46]. Campus Connectedness Scale (CCS). The CCS is a self-report measure designed to assess the degree of belongingness students' feel towards their university campus [33]. The CCS consists of 14 items, measured on a 6-point Likert Scale.

The Depression Anxiety Stress Scale-21 (DASS-21). The DASS-21 is a self-report scale developed by Lovibond and Lovibond [38], designed to assess the negative emotional states of depression, anxiety, and stress. The DASS-21 includes 21 items, measured on a 4-point Likert Scale, with higher scores indicative of higher levels of depression, anxiety, or stress. Due to using the shortened version (DASS-21) rather than the original DASS-42, scores must be multiplied by two. 


\section{Results}

Prior to conducting the MANOVA, Pearson's correlations were performed on resilience, perceived social support, campus connectedness, and psychological distress, as can be seen in Table 1. In line with the hypotheses, significant correlations were observed between all variables, with moderate effect sizes [47]. Results revealed perceived social support to have a positive association with resilience $(r=0.39, p<0.001)$, inferring that, as scores on resilience increased, scores on perceived social support also increased. Resilience also depicted a positive association with campus connectedness $(r=0.42, p<0.001)$, suggesting that as scores on resilience increase, scores on campus connectedness also increased. As expected, an inverse association between resilience and psychological distress was revealed $(r=-0.52, p<0.001)$ suggesting that, as scores on resilience increased, scores on psychological distress decreased.

Prior to conducting the main analysis, an ANOVA was conducted to investigate any significant differences between university classification (Australian, USA, Hong Kong) on dependent variables. No significant difference was found between these samples, on perceived social support $F(2,204)=2.77, p=0.065$, campus connectedness $F(2,213)=1.45, p=0.236$, or psychological distress $F(2,213)=2.64, p=0.074$. Due to no significant difference being found between these sample, samples were merged to create one large, international sample.

A one-way between groups MANOVA was conducted to test the hypothesis that levels of perceived social support, campus connectedness, and psychological distress would show a significant difference between university students who reported high levels of resilience, in comparison to university students who reported low levels of resilience. Students were classified intro groups of resilience through a tertile split. Due to examining high levels in comparison to low levels of resilience, middle scores were not used. Findings showed a significant multivariate main effect for resilience, $F(1,126)=23.36, p<0.001, \tilde{\eta}^{2}=0.357$, power $\Rightarrow 1$, with resilience levels accounting for $36 \%$ of total variance in the dependent variables.

Given the significant multivariate main effect, investigation of univariate analyses of variance were assessed for each dependent variable. Levene's test of homogeneity showed to be non-significant across all dependent variables, inferring the data set had equal variance across the sample. Results showed significant univariate effects for resilience (high resilience versus low resilience) across the dependent variables of perceived social support, $F(1,128)=37.02, p<0.001, \tilde{\eta}^{2}=0.224$, power $\Rightarrow 1$, campus connectedness, $F(1,128)=32.57, p<$ $0.001, \tilde{\eta}^{2}=0.203$, power $\Rightarrow 1$, and psychological distress, $F(1,128)=49.77, p<0.001, \tilde{\eta}^{2}=0.280$, power $\Rightarrow 1$. Table 2 displays the means and standard deviations for the dependent variables between groups of high and low levels of resilience. As noted in Table 2, the high resilience group reported significantly higher levels of perceived social support and campus connectedness compared to the low resilience group. Furthermore, the high resilience group reported significantly lower levels of psychological distress, when compared with the low resilience group.

Table 1. Summary of intercorrelations, uncentered means, and standard deviations for resilience, perceived social support, campus connectedness, and psychological distress $(\mathrm{N}=214)$.

\begin{tabular}{ccccccc}
\hline Variable & 1. & 2. & 3. & 4. & $M$ & SD \\
\hline 1. Resilience & - & & & & 133.26 & 18.38 \\
2. Perceived Social Support & $0.39^{* * *}$ & - & & & 68.22 & 11.60 \\
3. Campus Connectedness & $0.42^{* * *}$ & $0.54^{* * *}$ & - & 60.00 & 14.10 \\
4. Psychological Distress & $-0.52^{* * *}$ & $-0.22^{* * *}$ & $-0.45^{* * *}$ & - & 26.74 & 18.68 \\
\hline Note $^{* * *}{ }^{*}<0.001$ & & & & & &
\end{tabular}

Table 2. Means and standard deviations between groups (high versus low resilience), perceived social support, campus connectedness, and psychological distress $(N=130)$.

\begin{tabular}{ccc}
\hline Variable & High Resilience $(N=69)$ & Low Resilience $(N=61)$ \\
\cline { 2 - 3 } & $M(\mathrm{SD})$ & $M(\mathrm{SD})$ \\
\hline Perceived Social Support & $74.93(9.85)$ & $53.68(11.09)$ \\
Campus Connectedness & $67.34(13.34)$ & $35.97(16.51)$ \\
Psychological Distress & $16.38(14.96)$ & $35)$ \\
\hline
\end{tabular}




\section{Discussion}

The purpose of the current study was to investigate characteristics of resilience among university students. Specifically, the study's objective was to examine university students with high and lows levels of resilience on modifiable psychosocial factors such as perceived social support, campus connectedness, and psychological distress. Current literature supports the associations between these variables and resilience; however, is limited in terms of examining differences in characteristics between university students reporting high or low levels of resilience. Additionally, to the authors' knowledge, no studies to date have examined the relationship between resilience and campus connectedness in the university context. The current study addressed commonly cited limitations in the literature, by using a diverse and global sample, allowing for greater insight into resilience across diverse university populations.

Hypothesis one predicted that a significant positive correlation would exist between resilience and perceived social support, and resilience and campus connectedness, while a significant negative correlation would exist between resilience and psychological distress. Results supported this hypothesis. Findings were consistent with previous research in that a significant positive association was observed between resilience and perceived social support, with higher levels of resilience associated with higher levels of perceived social support [26] [27]. Additionally, novel to investigation, resilience showed a significant positive association with campus connectedness, with higher levels of resilience associated with higher levels of campus connectedness. Furthermore as predicted, the current study found a significant negative association between resilience and psychological distress, supporting previous research by Hjemdal et al. [37], that found higher levels of resilience were associated with lower levels of psychological distress.

Hypothesis two predicted that, in comparison to university students reporting high levels of resilience, university students reporting low levels of resilience would report significantly: lower levels of perceived social support, lower levels of campus connectedness, and higher levels of psychological distress. Results provided support for this hypothesis. Results from the MANOVA, showed the multivariate main effect of resilience found statistically significant differences between university students with high levels of resilience, and university students with low levels of resilience. The main effect of resilience accounted for $36 \%$ of variance in the dependent variables, inferring that university student's levels of resilience played a significant role in depicting scores on the combined measured variables of perceived social support, campus connectedness, and psychological distress.

As predicted, university students with low levels of resilience reported significantly lower levels of perceived social support in comparison to university students with high levels of resilience. These results are consistent with previous findings, in that perceived social support was associated with higher levels of resilience among university students [25]-[27]. This finding suggests that university students with high levels of resilience showed a greater perception of social support from family, friends, and significant others. Consistent with previous research, high levels of perceived social support is not only linked with high resilience, but also linked with greater psychological wellbeing [12]. With this in mind, the implementation of informal perceived social support interventions within the university environment may be significantly helpful in cultivating resilience, improving the mental health of university students, and also potentially increasing student retention.

Furthermore, as predicted, university students with low levels of resilience reported significantly lower levels of campus connectedness in comparison to university students with high levels of resilience. Due to the positive association shown between resilience and campus connectedness, universities may wish to focus on extra curricular activities that foster connectedness to assist in facilitating greater resilience among the university population.

Additionally as predicted, university students with low levels of resilience reported significantly higher levels of psychological distress in comparison to university students with high levels of resilience. This finding supports the associations made in the literature between resilience and psychological distress, in that university students with lower resilience experience greater psychological distress [27] [37] [45] [48]. With statistics showing such high prevalence of psychological distress among the university population, interventions aimed to lower distress are increasing [48]. As such, universities may wish to focus on implementing specific programs targeted towards enhancing a student's levels of resilience to ultimately reduce psychological distress.

Overall, the dependent variables explained $36 \%$ of the variance in resilience levels, leaving $64 \%$ of the variance unexplained. Future studies may wish to explore additional characteristics that may account for signifi- 
cant differences between university students with high levels of resilience and university students with low levels of resilience. Limitations of the current study were noted. As with any research using self-report measures, social desirability was a concern. An additional line of research may wish to assess university students through self-report methods as well as through an external evaluator, such as a classmate. Such an approach may provide an additional perspective and resolve some of the limitations evident in self-report procedures [6]. The possibility of response set bias should also be noted when interpreting results, as the measurement scales used, incorporated limited reverse scoring. Therefore, caution must be taken upon interpretation, and future research should ensure items and measures are counterbalanced to control for potential response set bias among participants. Furthermore, the current study should be replicated using a larger sample. Due to recruiting participants via methods of convenience sampling, participants were not representative of the global university population, limiting the ability to generalise findings.

In combination, these findings made a valuable contribution to the body of literature examining resilience among university students and to the limited research on campus connectedness and resilience within the university context. Additionally, the current study is among the first to systematically explore the difference between university students with high and low levels of resilience, across levels of perceived social support, campus connectedness, and psychological distress. As such, the current study's findings have made a significant contribution to the knowledge surrounding resilience in the university environment, through gaining a deeper understanding of the characteristics of resilient university students, who can succeed despite adversity. The significant findings from the current study shows promise for identifying factors associated with resilience among the university populations, which in turn can provide a basis for developing and implementing resilience-boosting programs for this population. This will facilitate a myriad of benefits to not only university students but also the wider community.

\section{References}

[1] Pittman, L.D. and Richmond, A. (2008) University Belonging, Friendship Quality, and Psychological Adjustment during the Transition to College. The Journal of Experimental Education, 76, 343-362. http://dx.doi.org/10.3200/JEXE.76.4.343-362

[2] Pratt, M.W. (2000) The Transition to University Contexts, Connections, and Consequences. Journal of Adolescent Research, 15, 5-8. http://dx.doi.org/10.1177/0743558400151001

[3] Tavolacci, M.P., Ladner, J., Grigioni, S., Richard, L., Villet, H. and Dechelotte, P. (2013) Prevalence and Association of Perceived Stress, Substance Use and Behavioral Addictions: A Cross-Sectional Study among University Students in France, 2009-2011. BMC Public Health, 13, 724. http://dx.doi.org/10.1186/1471-2458-13-724

[4] Hiester, M., Nordstrom, A. and Swenson, L.M. (2009) Stability and Change in Parental Attachment and Adjustment Outcomes during the First Semester Transition to College Life. Journal of College Student Development, 50, 521-538. http://dx.doi.org/10.1353/csd.0.0089

[5] Stallman, H.M. (2010) Psychological Distress in University Students: A Comparison with General Population Data. Australian Psychologist, 45, 249-257. http://dx.doi.org/10.1080/00050067.2010.482109

[6] Machuca, J.R. (2010) Resilience Characteristics of Master's-Level Counseling Students. Doctoral Dissertation, University of New Orleans, New Orleans. http://scholarworks.uno.edu/td/1272/

[7] Adlaf, M., Gliksman, L., Demers, A. and Newton-Taylor, B. (2001) The Prevalence of Elevated Psychological Distress among Canadian Undergraduates: Findings from the 1998 Canadian Campus Survey. Journal of American College Health, 50, 67-72. http://dx.doi.org/10.1080/07448480109596009

[8] Belfer, M.L. (2008) Child and Adolescent Mental Disorders: The Magnitude of the Problem across the Globe. Journal of Child Psychology and Psychiatry, 49, 226-236. http://dx.doi.org/10.1111/j.1469-7610.2007.01855.x

[9] Wintre, M.G. and Yaffe, M. (2000) First-Year Students’ Adjustment to University Life as a Function of Relationships with Parents. Journal of Adolescent Research, 15, 9-37. http://dx.doi.org/10.1177/0743558400151002

[10] Wang, J. (2009) A Study of Resiliency Characteristics in the Adjustment of International Graduate Students at American Universities. Journal of Studies in International Education, 13, 22-45. http://dx.doi.org/10.1177/1028315307308139

[11] Abbott, J.A., Klein, B., Hamilton, C. and Rosenthal, A. (2009) The Impact of Online Resilience Training for Sales Managers on Wellbeing and Work Performance. Electronic Journal of Applied Psychology: General Articles, 5, 89-95. http://dx.doi.org/10.7790/ejap.v5i1.145

[12] Bovier, P.A., Chamot, E. and Perneger, T.V. (2004) Perceived Stress, Internal Resources, and Social Support as De- 
terminants of Mental Health among Young Adults. Quality of Life Research, 13, 161-170. http://dx.doi.org/10.1023/B:QURE.0000015288.43768.e4

[13] Beeber, L.S. (1999) Testing an Explanatory Model of the Development of Depressive Symptoms in Young Women during a Life Transition. Journal of American College Health, 47, 227-234. http://dx.doi.org/10.1080/07448489909595652

[14] Edwards, K.J., Hershberger, P.J., Russell, R.K. and Markert, R.J. (2001) Stress, Negative Social Exchange, and Health Symptoms in University Students. Journal of American College Health, 50, 75-79. http://dx.doi.org/10.1080/07448480109596010

[15] Wagnild, G.M. and Collins, J.A. (2009) Assessing Resilience. Journal of Psychosocial Nursing and Mental Health Services, 47, 28-33. http://dx.doi.org/10.3928/02793695-20091103-01

[16] Wagnild, G.M. and Young, H.M. (1993) Development and Psychometric Evaluation of the Resilience Scale. Journal of Nursing Measurement. http://www.sapibg.org/attachments/article/1054/wagnild_1993_resilience_scale_2

[17] Ahern, N.R., Kiehl, E.M., Sole, M.L. and Byers, J. (2006) A Review of Instruments Measuring Resilience. Issues in Comprehensive Pediatric Nursing, 29, 103-125. http://dx.doi.org/10.1080/01460860600677643

[18] Luthar, S.S., Cicchetti, D. and Becker, B. (2000) The Construct of Resilience: A Critical Evaluation and Guidelines for Future Work. Child Development, 71, 543-562. http://dx.doi.org/10.1111/1467-8624.00164

[19] Connor, K.M. and Davidson, J.R. (2003) Development of a New Resilience Scale: The Connor-Davidson Resilience Scale (CD-RISC). Depression and Anxiety, 18, 76-82. http://dx.doi.org/10.1002/da.10113

[20] Gilligan, R. (2007) Adversity, Resilience and the Educational Progress of Young People in Public Care. Emotional and Behavioural Difficulties, 12, 135-145. http://dx.doi.org/10.1080/13632750701315631

[21] Jackson, D., Firtko, A. and Edenborough, M. (2007) Personal Resilience as a Strategy for Surviving and Thriving in the Face of Workplace Adversity: A Literature Review. Journal of Advanced Nursing, 60, 1-9. http://dx.doi.org/10.1111/j.1365-2648.2007.04412.x

[22] DeRosier, M., Frank, E., Schwartz, V. and Leary, K. (2013) The Potential Role of Resilience Education for Preventing Mental Health Problems for College Students. Psychiatric Annals, 43, 538-544. http://dx.doi.org/10.3928/00485713-20131206-05

[23] Peng, L., Zhang, J., Li, M., Li, P., Zhang, Y., Zuo, X. and Xu, Y. (2012) Negative Life Events and Mental Health of Chinese Medical Students: The Effect of Resilience, Personality, and Social Support. Psychiatry Research, 196, 138. http://dx.doi.org/10.1016/j.psychres.2011.12.006

[24] Phinney, J.S. and Hass, K. (2003) The Process of Coping among Ethnic Minority First-Generation College Freshmen: A Narrative Approach. The Journal of Social Psychology, 143, 707-726. http://dx.doi.org/10.1080/00224540309600426

[25] Wang, C.D. and Castaneda-Sound, C. (2008) The Role of Generational Status, Self-Esteem, Academic Self-Efficacy and Perceived Social Support in College Students’ Psychological Well-Being. Journal of College Counseling, 11, 101-118. http://dx.doi.org/10.1002/j.2161-1882.2008.tb00028.x

[26] Wilks, S.E. (2008) Resilience Amid Academic Stress: The Moderating Impact of Social Support among Social Work Students. Advances in Social Work, 9, 106-125.

https://advancesinsocialwork.iupui.edu/index.php/advancesinsocialwork/article/view/51/195

[27] Wilks, S.E. and Spivey, C.A. (2010) Resilience in Undergraduate Social Work Students' Social Support and Adjustment to Academic Stress. Social Work Education, 29, 276-288. http://dx.doi.org/10.1080/02615470902912243

[28] Ogrodniczuk, J.S., Joyce, A.S. and Piper, W.E. (2003) Changes in Perceived Social Support after Group Therapy for Complicated Grief. The Journal of Nervous and Mental Disease, 191, 524-530. http://dx.doi.org/10.1097/01.nmd.0000082180.09023.64

[29] Uchino, B.N. (2009) Understanding the Links between Social Support and Physical Health: A Life-Span Perspective with Emphasis on the Separability of Perceived and Received Support. Perspectives on Psychological Science, 4, 236255. http://dx.doi.org/10.1111/j.1745-6924.2009.01122.x

[30] Ryan, R.M. and Deci, E.L. (2000) Self-Determination Theory and the Facilitation of Intrinsic Motivation, Social Development, and Well-Being. American Psychologist, 55, 68. http://dx.doi.org/10.1037/0003-066X.55.1.68

[31] Bruwer, B., Emsley, R., Kidd, M., Lochner, C. and Seedat, S. (2008) Psychometric Properties of the Multidimensional Scale of Perceived Social Support in Youth. Comprehensive Psychiatry, 49, 195-201. http://dx.doi.org/10.1016/j.comppsych.2007.09.002

[32] Cohen, S. and Wills, T.A. (1985) Stress, Social Support, and the Buffering Hypothesis. Psychological Bulletin, 98, 310. http://dx.doi.org/10.1037/0033-2909.98.2.310

[33] Lee, R.M. and Robbins, S.B. (2000) Understanding Social Connectedness in College Women and Men. Journal of 
Counseling and Development, 78, 484-491.

[34] Reivich, K. and Shatté, A. (2002) The Resilience Factor: 7 Essential Skills for Overcoming Life’s Inevitable Obstacles. Broadway Books.

[35] Tinto, V. (1975) Dropout from Higher Education: A Theoretical Synthesis of Recent Research. Review of Educational Research, 45, 89-125. http://dx.doi.org/10.3102/00346543045001089

[36] Milem, J.F. and Berger, J.B. (1997) A Modified Model of College Student Persistence: Exploring the Relationship between Astin's Theory of Involvement and Tinto’s Theory of Student Departure. Journal of College Student Development, 38, 387-400. http://works.bepress.com/joseph_berger/31

[37] Hjemdal, O., Friborg, O., Stiles, T.C., Rosenvinge, J.H. and Martinussen, M. (2006) Resilience Predicting Psychiatric Symptoms: A Prospective Study of Protective Factors and Their Role in Adjustment to Stressful Life Events. Clinical Psychology and Psychotherapy, 13, 194-201. http://dx.doi.org/10.1002/cpp.488

[38] Lovibond, S.H. and Lovibond, P.F. (1995) Manual for the Depression Anxiety Stress Scales. 2nd Edition, Psychology Foundation, Sydney.

[39] Henry, J.D. and Crawford, J.R. (2005) The Short-Form Version of the Depression Anxiety Stress Scales (DASS-21): Construct Validity and Normative Data in a Large Non-Clinical Sample. British Journal of Clinical Psychology, 44, 227-239. http://dx.doi.org/10.1348/014466505X29657

[40] Byrd, D.R. and McKinney, K.J. (2012) Individual, Interpersonal, and Institutional Level Factors Associated with the Mental Health of College Students. Journal of American College Health, 60, 185-193. http://dx.doi.org/10.1080/07448481.2011.584334

[41] American College Health Association (2012) American College Health Association-National College Health Assessment II: Reference Group Executive Summary. http://www.acha-ncha.org/docs/ACHA-NCHA-II_ReferenceGroup_ExecutiveSummary_Spring2012

[42] Gould, M.S., Greenberg, T.E.D., Velting, D.M. and Shaffer, D. (2003) Youth Suicide Risk and Preventive Interventions: A Review of the Past 10 Years. Journal of the American Academy of Child and Adolescent Psychiatry, 42, 386405. http://dx.doi.org/10.1097/01.CHI.0000046821.95464.CF

[43] Wong, J.G.W.S., Cheung, E.P.T., Chan, K.K.C., Ma, K.K.M. and Tang, S.W. (2006) Web-Based Survey of Depression, Anxiety and Stress in First-Year Tertiary Education Students in Hong Kong. Australian and New Zealand Journal of Psychiatry, 40, 777-778. http://dx.doi.org/10.1111/j.1440-1614.2006.01883.X

[44] Chen, L., Wang, L., Qiu, X.H., Yang, X.X., Qiao, Z.X., Yang, Y.J. and Liang, Y. (2013) Depression among Chinese University Students: Prevalence and Socio-Demographic Correlates. PloS One, 8. http://dx.doi.org/10.1371/journal.pone.0058379

[45] Storrie, K., Ahern, K. and Tuckett, A. (2010) A Systematic Review: Students with Mental Health Problems-A Growing Problem. International Journal of Nursing Practice, 16, 1-6. http://dx.doi.org/10.1111/j.1440-172X.2009.01813.x

[46] Zimet, G.D., Powell, S.S., Farley, G.K., Werkman, S. and Berkoff, K.A. (1990) Psychometric Characteristics of the Multidimensional Scale of Perceived Social Support. Journal of Personality Assessment, 55, 610-617. http://dx.doi.org/10.1080/00223891.1990.9674095

[47] Cohen, J. (1992) Statistical Power Analysis. Current Directions in Psychological Sciences, 1, 98-101. http://dx.doi.org/10.1111/1467-8721.ep10768783

[48] Steinhardt, M. and Dolbier, C. (2008) Evaluation of a Resilience Intervention to Enhance Coping Strategies and Protective Factors and Decrease Symptomatology. Journal of American College Health, 56, 445-453. http://dx.doi.org/10.3200/JACH.56.44.445-454 